\title{
Optimisation Study of Co Deposition on Chars from MAP of Waste Tyres as Green Electrodes in ORR for Alkaline Fuel Cells
}

\author{
Maurizio Passaponti ${ }^{1, *,+}$, Leonardo Lari ${ }^{2,3,+} \mathbb{D}$, Marco Bonechi ${ }^{1}$, Francesca Bruni ${ }^{1}$, \\ Walter Giurlani ${ }^{1}{ }^{\circledR}$, Gabriele Sciortino ${ }^{1}$, Luca Rosi ${ }^{1}{ }^{\circledR}$, Lorenzo Fabbri ${ }^{1}{ }^{\circledR}$, Martina Vizza ${ }^{1}$, \\ Vlado K. Lazarov ${ }^{2,3}$, Claudio Fontanesi 4 (D) and Massimo Innocenti ${ }^{1, *(D)}$ \\ 1 Department of Chemistry "Ugo Schiff", University of Florence, via della Lastruccia 3, \\ 50019 Sesto Fiorentino, Italy; marco.bonechi1@stud.unifi.it (M.B.); francesca.bruni3@stud.unifi.it (F.B.); \\ walter.giurlani@unifi.it (W.G.); gabriele.sciortino@outlook.it (G.S.); luca.rosi@unifi.it (L.R.); \\ lorenzo.fabbri@unifi.it (L.F.); martina.vizza@unifi.it (M.V.) \\ 2 Physics Department, University of York, Heslington, York YO10 5DD, UK; leonardo.lari@york.ac.uk (L.L.); \\ vlado.lazarov@york.ac.uk (V.K.L.) \\ 3 The York-JEOL Nanocentre, Helix House, Science Park, Heslington, York YO10 5BR, UK \\ 4 Department of Engineering 'Enzo Ferrari', University of Modena and Reggio Emilia, Via Vivarelli 10, \\ 41125 Modena, Italy; claudio.fontanesi@unimore.it \\ * Correspondence: maurizio.passaponti@unifi.it (M.P.); m.innocenti@unifi.it (M.I.) \\ + M.P. and L.L contributed equally to the manuscript.
}

Received: 28 September 2020; Accepted: 26 October 2020; Published: 28 October 2020

\begin{abstract}
Oxygen Reduction Reaction (ORR) catalysts, from waste automobile tyres obtained from Microwave assisted pyrolysis (MAP), were enriched with $\mathrm{Co}$ and $\mathrm{Cu}$ using the simple treatments sonochemical and electrochemical deposition. Catalytic activity was evaluated through onset potential and number of exchanged electrons measurements. Electrochemical data demonstrate an improvement in catalytic activity of the electrochemical modified char with Co. Char electrodes enriched with Co show a maximum positive shift of $40 \mathrm{mV}$ with respect to raw char electrodes with a number of exchanged electrons per $\mathrm{O}_{2}$ molecule close to 4 (as for $\mathrm{Pt}$ ) for the best sample. This corresponds to a reduction of the production of unwanted oxygen peroxide from $23 \%$ for raw char to $1 \%$. Sample structure evolution before and after electrochemical deposition and electro-catalysis was investigated by scanning transmission electron microscopy and XPS. Such electrochemical treatments open new possibilities of refining waste chars and finding an economic alternative to noble metals-based catalysts for alkaline fuel cells.
\end{abstract}

Keywords: ORR; waste-tyres; electrodeposition; cobalt

\section{Introduction}

End of life tyres (ELTs) show a difficult disposal and recycling process. Their methods of recovery can be divided in three main types: physical, chemical and thermal. In the last method, we seek a way of recovering energy from ELTs using pyrolysis [1]. As a result of this process, chars are obtained as discard products. During pyrolysis, thermochemical decomposition stimulates a series of radical chain reactions that deconstruct polymers into smaller compounds [2]. The presence of carbon black, an excellent absorber, employed as filler in ELTs, enables the use of microwave pyrolysis, in which electromagnetic energy is transformed into thermal energy [3], and allows uniform heating [4]. Chars obtained by pyrolysis can be used to produce electrocatalysts for fuel cells. Their catalytic activity depends on the presence of metals that speed up the ORR kinetics [5] coupled with their high 
porosity that allows to absorb large oxygen amounts [1,6-11]. In previous studies, the ORR efficiency was stated to depend on the power $/$ mass $^{2}\left(\mathrm{P} / \mathrm{M}^{2}\right)$ ratio obtained through pyrolysis: a higher $\mathrm{P} / \mathrm{M}^{2}$ ratio leads to an increase in catalytic activity due to an increase in chars porosity [12].

The aim of this work was to improve the activity of raw chars using simple and cheap methods. Considering the catalytic activities of single metals in chars, $\mathrm{Co}$ and $\mathrm{Cu}$ show a synergic activity: the first one assists the electron transfer and the second enhances oxygen adsorption onto the electrode surface; in particular, $\mathrm{Co}$ is able to break the $\mathrm{O}-\mathrm{O}$ bond of $\mathrm{O}_{2}$ molecules, accelerating the first reaction step of ORR [5].

In the electrochemical potential range used to study ORR in alkaline electrolytes, the Co surface is partly oxidised to $\mathrm{Co}(\mathrm{OH})_{2}[13,14]$ : the hydroxide promotes a two-electron pathway and shows an autocatalytic mechanism with an intermediate step, where oxygen is again formed [15-17].

The development of nanomaterials in electrochemistry has burgeoned in the last decades, specifically in electrodes production [18-20]. Modified electrodes appear to be better than macroelectrodes on different aspects, such as increased mass transfer, catalytic efficiency, active sites and superficial area [21]. The cheapest electrodes can be produced by doping cheap materials with nanoparticles [22] which can increase peak current and reduce overpotential promoting reaction kinetics [23,24]. Particles at the nanometre scale can be obtained by using different ways: (i) chemical reduction from colloidal solution; (ii) electrodeposition [25]; and (iii) sonochemical reduction. In this work, we applied the last two methods to increase cobalt and copper amount in ELTs chars. During electrochemical deposition, a potential on the working electrode is applied to produce the necessary current to reduce ions [26]. The metal mass deposed on the electrode is directly proportional to the total charge and its equivalent weight according to Faraday's first law [27]. Among the advantages of electrodeposition there is the chance of working in easy conditions of pressure and temperature. In addition, it represents a good method to limit the amount of deposited metals, allowing the formation of thin and homogeneous deposits. Glassy carbon electrodes modified with electrochemical deposition of small amounts of Co have shown an increase in their catalytic activity in ORR in an alkaline medium [28]; specifically, a shift to more positive values in the onset potential and in the limit current is observed. Sonochemical reduction of precious metals $[29,30]$ has been reported to allow an easy and inexpensive deposition method for thin layers of nanoparticles over mesoporous materials as activated carbon without obstructing pores [31]. The dimension of nanoparticles depends on the type of surfactant used and its concentration [32].

In this study, for the first time, we combined the use of cheap electrodes made of chars obtained from recycled tyre waste with the enrichment of earth abundant (and cheap) metals, namely Co and $\mathrm{Cu}$. We report on the optimisation of metal enrichment by comparing deposition methods and effective amount of metal deposited with their electrocatalytic performance. In addition, the evolution of deposited materials on the optimised electrode before and after electrocatalysis was monitored using scanning transmission electron microscopy (STEM) and X-Ray photoelectron spectroscopy (XPS).

\section{Materials and Methods}

Char materials were obtained from Michelin tyres (model Agilis 81 195/65 R16C) using the experimental conditions defined in [33]. Tyres were fragmented and dried in an oven with a temperature of $65{ }^{\circ} \mathrm{C}$ for $48 \mathrm{~h}$. Dried fragments were pyrolysed in a microwave oven MW Lab Unit (Microglass) working at $2.45 \mathrm{GHz}$ with a maximum power of $2.4 \mathrm{~kW}$. The solid residue was homogenised obtaining raw chars. The sample with the highest power $/ \mathrm{mass}^{2}\left(\mathrm{P} / \mathrm{M}^{2}\right)$ ratio during pyrolysis (see [12]) was labelled "CHraw" and was selected for the metal enrichment process below. 


\subsection{Deposition Techniques}

\subsubsection{Sonochemical Deposition}

Sonochemical deposition was applied to the CHraw sample following the experimental procedures reported in [34,35]. Co nanoparticles were prepared from an aqueous solution $0.2 \mathrm{M}$ of cobalt hydroxide carbonate $\left(\mathrm{Co}_{2} \mathrm{CO}_{3}(\mathrm{OH})_{2}\right)$ with the addition of citric acid $0.05 \mathrm{M}$ to favour the carbonate dissolution and control nanoparticles' structure and dimensions. Similarly, $\mathrm{Cu}$ nanoparticles were prepared from a similar solution with $\mathrm{CuCl}_{2}$.

A volume $(5 \mathrm{~mL})$ of ethanol and $25 \mathrm{mg}$ of chars were added to the solution and then sonicated for $90 \mathrm{~min}$. At the end of the deposition, samples were dried and centrifuged at room temperature to speed up the drying process to obtain two sets of samples: char with sonochemically deposited $\mathrm{Cu}$ and Co labelled, respectively, "CHscCu" and "CHscCo".

\subsubsection{Electrochemical Deposition}

Electrochemical deposition of Co was performed using a char based ink (using sample CHraw) and dropcasting on a glassy carbon electrode, using the method described in [28]. To determine the optimal potential and experimental conditions for the deposition, a cyclic voltammetry on the ink in a solution of $5 \times 10^{-3} \mathrm{M} \mathrm{Co}$ (II)in buffer solution $\mathrm{NH}_{4} \mathrm{OH} / \mathrm{HClO}_{4}(\mathrm{pH}=9.2$ ) (see Figure S1) was performed. The deposition was then conducted through chronoamperometry with a constant potential of $-850 \mathrm{mV}$ (vs. $\mathrm{Ag} / \mathrm{AgCl}$ in $\mathrm{KCl}$ sat.) under constant magnetic stirring. Before the deposition, to clean the deposited ink surface, a linear scanning voltammetry of stripping from -750 to $600 \mathrm{mV}$ (vs. Ag/AgCl in $\mathrm{KCl}$ sat.) with a scan rate of $10 \mathrm{mV} / \mathrm{s}$, in a cleansing solution, was performed. The electrode was transferred in a beaker containing $50 \mathrm{~mL}$ of Co (II) solution, previously flushed with $\mathrm{N}_{2}$ for $30 \mathrm{~min}$. Chronoamperometry with a constant potential of $-850 \mathrm{mV}$ (vs. $\mathrm{Ag} / \mathrm{AgCl}$ in $\mathrm{KCl}$ sat.) was performed as a function of time to make a cobalt electrochemical deposition series with electrodepositions lasting 5, 15, 30, 60 and $90 \mathrm{~s}$ (see Figure S2). The resulting samples were labelled as "CHecCo5s", "CHecCo15s", "CHecCo30s", "CHecCo60s", and "CHecCo90s", respectively. The amount of Co deposited on the electrode was calculated by Faraday's laws of electrolysis and measured by inductively coupled plasma atomic emission spectroscopy (ICP-AES) (see Section 2.2.1). Deposited quantities are reported in Table 1. The stability of the deposited material was confirmed by stripping linear sweep voltammetry (LSV) where no dissolution peak is observed (as shown in Figure S3).

Table 1. Deposited charge related to different Co deposition time and associated deposited mass per electrode.

\begin{tabular}{cccc}
\hline Sample & Time (s) & Charge (C) & Deposited Mass (mg) \\
\hline CHecCo5s & 5 & $1.97 \times 10^{-3}$ & $6.02 \times 10^{-4}$ \\
CHecCo15s & 15 & $3.67 \times 10^{-3}$ & $1.12 \times 10^{-3}$ \\
CHecCo30s & 30 & $5.874 \times 10^{-3}$ & $1.79 \times 10^{-3}$ \\
CHecCo60s & 60 & $7.36 \times 10^{-3}$ & $2.25 \times 10^{-3}$ \\
CHecCo90s & 90 & $1.017 \times 10^{-2}$ & $3.11 \times 10^{-3}$ \\
\hline
\end{tabular}

\subsection{Characterisation}

\subsubsection{ICP-AES}

Metal content deposition was evaluated through ICP-AES analysis, carried out using a microwave mineraliser, (CEM Mars Xpress) and a spectrophotometer with inductively coupled argon plasma (Perkin Elmer Optima 2000 OES DV). The results are reported in Table 2. 
Table 2. Metal content from ICP-AES analysis after sonochemical $(\mathrm{CHsc})$ and electrochemical $(\mathrm{CHec})$ deposition of $\mathrm{Cu}$ and $\mathrm{Co}$ on CHraw. Values in ppm $(\mathrm{mg} / \mathrm{kg})$ and $\mathrm{mg}$ present in $20 \mu \mathrm{L}$ of ink.

\begin{tabular}{ccccc}
\hline Sample & Cu (ppm) & $\mathbf{C u}(\mathbf{m g})$ & Co $(\mathbf{p p m})$ & Co $(\mathbf{m g})$ \\
\hline CHraw & 38.5 & $8.47 \times 10^{-6}$ & 162 & $3.56 \times 10^{-5}$ \\
$\mathrm{CHscCu}$ & 1140 & $2.21 \times 10^{-4}$ & & \\
CHscCo & & & 235,000 & $5.17 \times 10^{-2}$ \\
CHecCo5s & & 1800 & $3.96 \times 10^{-4}$ \\
CHecCo15s & & 4710 & $1.04 \times 10^{-3}$ \\
CHecCo30s & & 7140 & $1.57 \times 10^{-3}$ \\
CHecCo60s & & 13,600 & $2.98 \times 10^{-3}$ \\
CHecCo90s & & & 19,485 & $4.27 \times 10^{-3}$ \\
\hline
\end{tabular}

\subsubsection{Scanning Transmission Electron Microscopy}

Samples for STEM analyses were prepared by finely crushing powders of electrode material and depositing them directly onto $(10 \mathrm{~nm})$ holy carbon films supported by standard TEM copper grids following the procedure described in [36]. STEM analyses were performed using a double aberration corrected scanning/transmission electron microscope operating at $200 \mathrm{KeV}$ (JEM 2200FS, JEOL Japan Ltd.). High angle annular dark field (HAADF) STEM images were obtained using an inner collection semi-angle of $70 \mathrm{mrad}$ and an outer collection semi-angle of $180 \mathrm{mrad}$. STEM energy dispersive X-ray (EDX) analyses were done using a $100 \mathrm{~mm}^{2}$ UltraDry windowless EDX silicon drift detector and the Pathfinder ${ }^{\mathrm{TM}}$ X-ray microanalysis software (Noran system 7, Thermo Fisher Scientific Inc.) for data analysis and display.

\subsubsection{X-ray Photoelectron Spectroscopy (XPS)}

XPS was done in ultra-high vacuum conditions (UHV) with an Al K $\alpha$ X-ray source at $1486.6 \mathrm{eV}$ (VSW Scientific Instrument Limited, model TA10) and a hemispheric magnetic analyser (VSW Scientific Instrument Limited, model HA100) with a 12-channel detector. The source power was set to $120 \mathrm{~W}$ with a 44-eV collection energy. Samples were transferred into the UHV chamber and cleaned with a low energy sputtering for 3 min before starting the analyses. Spectra were acquired with an energy dispersion of $0.5 \mathrm{eV} / \mathrm{channel}$ and $0.1 \mathrm{eV}$ for overview and high-resolution spectra acquisition, respectively. Spectra were analysed using CasaXPS software. Calibration was done fixing the energy of the aliphatic $\mathrm{C} 1 \mathrm{~s}$ transition at $284.8 \mathrm{eV}$ [37-39].

\subsubsection{Electrochemical Measurement}

Electrochemical characterisation involved cyclic voltammetry (CV) and LSV using Rotating Ring and Disk Electrode (RRDE). The experimental setting was composed by a cell containing a $0.1 \mathrm{M}$ $\mathrm{KOH}$ solution and three electrodes: (a) reference electrode $\mathrm{Ag} / \mathrm{AgCl} / \mathrm{KCl}$ saturated with a potential of $+0.197 \mathrm{~V}$ with respect to a Normal Hydrogen Electrode (NHE); (b) platinum wire as counter electrode; and (c) RRDE as working electrodes, consisting of a glassy carbon (GC) disk insert ( $\varnothing 5 \mathrm{~mm}$; $\left.\mathrm{A}=0.196 \mathrm{~cm}^{2}\right)$ and a Pt ring $\left(\mathrm{A}=0.11 \mathrm{~cm}^{2}\right)$. Each electrode was connected to a PGSTAT $100 \mathrm{~N}$ bi-potentiostat able to simultaneously record both disk and ring current. The RRDE electrode was attached to a modulated speed rotator (MSR) model 636 A from Pine Instrument Co.

Electrocatalytic activity of chars was tested preparing $0.5 \mathrm{~g}$ of an ink which contained catalyst $(2 \% \mathrm{wt} \%)$, water $(52 \% \mathrm{wt} \%)$, ethanol $(26 \% \mathrm{wt} \%)$ and Nafion solution $(20 \% \mathrm{wt} \%)$. The ink was sonicated for $30 \mathrm{~min}$ and drop-casted on the glassy carbon electrode using a $20 \mu \mathrm{L}$ pipette. The resulting electrode was dried at room temperature.

To verify the electrocatalytic activity of the samples, cyclic voltammetry was carried out with a potential range from +0.1 to $-0.85 \mathrm{~V}$ with a scan rate of $5 \mathrm{mV} / \mathrm{s}$. The $0.1 \mathrm{M} \mathrm{KOH}$ solution was saturated $\mathrm{O}_{2}$ gases. CVs representatives for all samples are reported in Figure S4. In all cases, a clear oxygen 
reduction peak is observed under $\mathrm{O}_{2}$ saturation. As a control experiment, with a saturation of the solution with $\mathrm{N}_{2}$, it was verified that the oxygen reduction peak was not observed.

Starting from these results, RRDE experiments were performed using a scan rate of $5 \mathrm{mV} / \mathrm{s}$ in the potential range from +0.1 to $-0.85 \mathrm{~V}$ (vs. $\mathrm{Ag} / \mathrm{AgCl} / \mathrm{sat} \mathrm{KCl}$ ) for the modified GC electrode while the $\mathrm{Pt}$ ring electrode was held at a potential of $+0.6 \mathrm{mV}$. Disk and ring current were obtained using RRDE electrode rotational speed of 1600 revolutions per minute (rpm). RRDE calibration was led for each sample determining empirically the collection efficiency number $(\mathrm{N})$ following the RRDE manufacturer (Pine Instrument Co) procedure through ring $\left(\mathrm{I}_{\mathrm{r}}\right) /$ disk $\left(\mathrm{I}_{\mathrm{d}}\right)$ current ratio $\left(\mathrm{N}=\mathrm{I}_{\mathrm{r}} / \mathrm{I}_{\mathrm{d}}\right)$ registered during LSV of a $\mathrm{N}_{2}$ saturated solution of $10 \mathrm{ppm} \mathrm{K}_{3} \mathrm{Fe}(\mathrm{CN})_{6}$ in $\mathrm{KCl} 0.1 \mathrm{M}$ at scan rate of $5 \mathrm{mV} / \mathrm{s}$ in the potential range of $+0.4 \mathrm{~V}$ to $-1.3 \mathrm{~V}$ and holding the ring with constant potential of $+0.6 \mathrm{~V}$ at $1600 \mathrm{rpm}$ (see Figure S5). Once $\mathrm{N}$ was determined, the electron transfer number exchanged per $\mathrm{O}_{2}$ molecule occurring during the ORR process (n) was calculated using Equation (1) [40], as reported in Figure S6.

$$
n=\frac{4 I_{\text {disk }}}{\left(I_{\text {disk }}+\frac{I_{\text {ring }}}{N}\right)}
$$

Based on the number of electrons exchanged per $\mathrm{O}_{2}$ molecule, the $\mathrm{H}_{2} \mathrm{O}$ and $\mathrm{H}_{2} \mathrm{O}_{2}$ percentages produced during the ORR process were calculated by Equation (2).

$$
\% \mathrm{H}_{2} \mathrm{O}_{2}=\left(2-\frac{n}{2}\right) \cdot 100
$$

The onset potential was estimated through the determination of the first derivative curve of the disk current SI (see Figure S7) [41]. The onset potential is the value of potential that coincides with the intersection among the curve tangent and the continuation of baseline.

\section{Results}

To evaluate the catalytic activity of electrocatalysts in ORR, we refer to parameters as the onset potential and the number of exchanged electrons. The onset potential represents the limit value at which a reaction starts to evolve in significant quantities while the number of exchanged electrons allows the assessment of the principal reaction pathway in ORR. A catalyst should preferably promote a four-electron exchange leading to $\mathrm{H}_{2} \mathrm{O}$ formation and avoid a two-electron exchange that results in $\mathrm{H}_{2} \mathrm{O}_{2}$ because of its negative influence on yields and corrosive effects on the membrane used in fuel cells. The results from linear sweep voltammetry (LSV) are reported in Figure 1. Electrochemical data (Table 3) demonstrate an improvement in catalytic activity of the electrochemical modified char.

Table 3. Synopsis of electrolytic data collected from sonochemical and electrochemical deposition of $\mathrm{Co}$ and $\mathrm{Cu}$.

\begin{tabular}{ccccc}
\hline Sample & Eon $(\mathbf{V})$ & $\mathbf{N}$ Experimental & $\mathbf{N ~ E m p}$ & $\mathbf{\%} \mathbf{H}_{\mathbf{2}} \mathbf{O}_{\mathbf{2}}$ \\
\hline CHraw & -0.21 & 3.53 & 0.25 & 23.5 \\
CHscCo & -0.225 & 2.91 & 0.20 & 54.5 \\
CHscCu & -0.183 & 3.19 & 0.21 & 40.5 \\
CHecCo5s & -0.184 & 3.94 & 0.25 & 3.0 \\
CHecCo15s & -0.180 & 3.95 & 0.25 & 2.5 \\
CHecCo30s & -0.172 & 3.98 & 0.25 & 1.0 \\
CHecCo60s & -0.184 & 3.96 & 0.25 & 2.0 \\
CHecCo90s & -0.193 & 3.94 & 0.25 & 3.0 \\
\hline
\end{tabular}

In the case of sonochemical deposition, it is possible to observe a worsening in catalytic activity compared to ink exclusively made of $\mathrm{CHraw}$. This can be attributed to an excess of material deposited (as confirmed by ICP-AES analysis). Co fully covering the char surface would prevent the correct adsorption of oxygen. This leads to more negative values of the onset potential compared to the one 
measured for CHraw. In addition, a decrease in exchanged electrons (around 2.90) is observed with a consequent increase in the percentage of hydrogen peroxide produced (around 15\%). Cu deposition brings worse catalysis yield, with a production of $40 \%$ of hydrogen peroxide ( 3.19 exchanged electrons). Ink samples of $\mathrm{CHraw}$ after Co electrodeposition showed an increased catalytic efficiency with respect to ink exclusively made of char. In fact, a higher onset potential of $-197 \mathrm{mV}$ was observed with an electron exchange close to 4 , and a production of hydrogen peroxide always under $2 \%$.

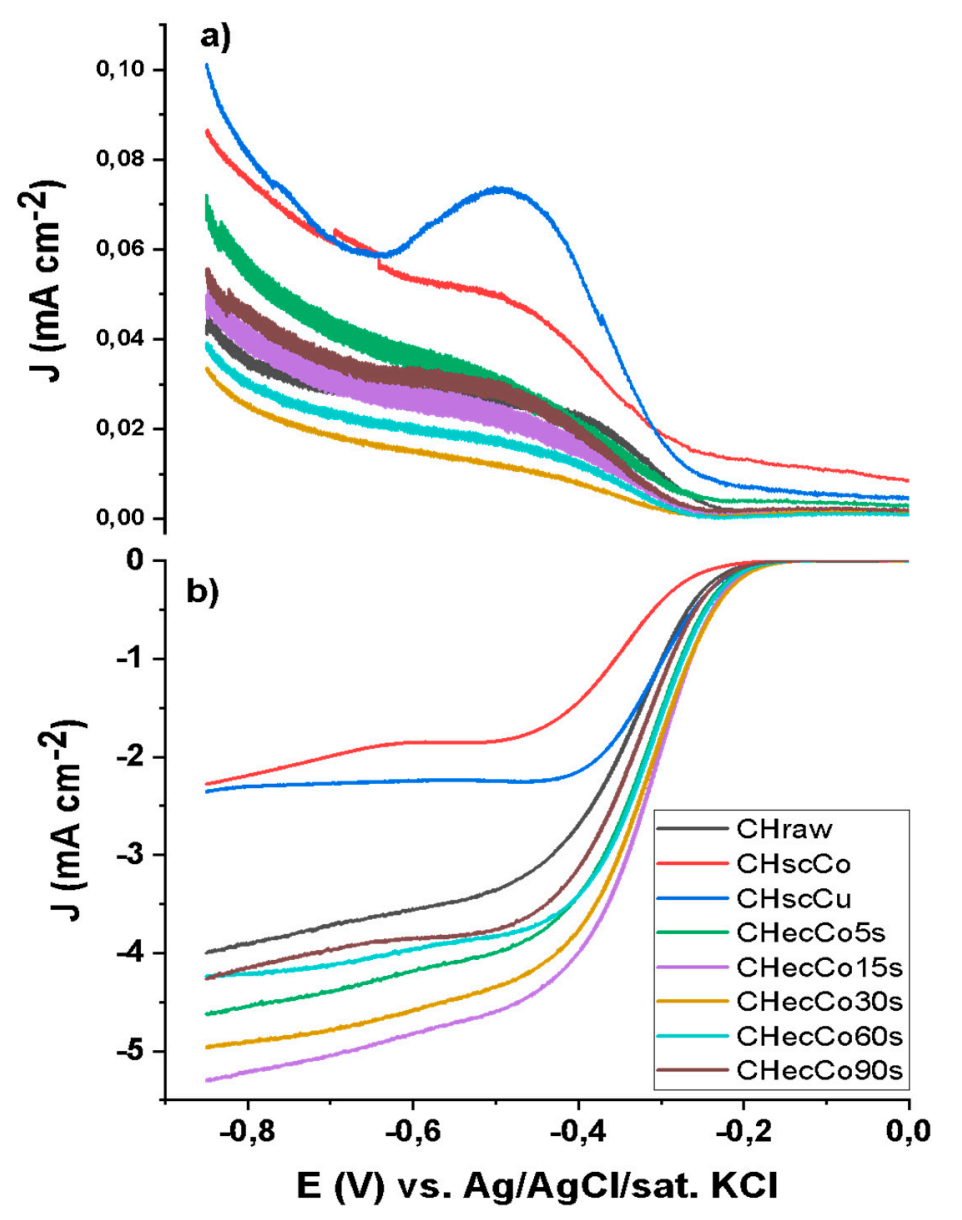

Figure 1. ORR RRDE electrocatalytic performance of samples obtained from sonochemical and electrochemical deposition of $\mathrm{Co}$ and $\mathrm{Cu}$ on CHraw: (a) ring; and (b) disk density of current.

In Figure 2, using the data shown in Figure 1 and Table 3, for the electrochemical deposition case, we plot the potential values as a function of deposition time, showing similar trends as for other materials in our previous study [28]. Data show a volcano-like trend, in agreement with Sabatier principle [42]. This is typical of a mechanism where the $\mathrm{O}_{2}$ adsorption is the rate-determining step. The increase in potential on the left branch of the "volcano" profile can be attributed to the increase of deposited Co onto the surface, while the decrease on the right branch can be associated with an excessive coverage in Co with a consequent reduced capability of oxygen adsorption from the underneath char. Alongside the increase in deposition time, a progressive enhancement in catalytic activity is observed, peaking at a deposition time of $30 \mathrm{~s}$. In this case, a substantial enhancement of all studied parameters is observed, obtaining an onset potential of $-172 \mathrm{mV}$, exchanged electrons up to 3.98 per $\mathrm{O}_{2}$ and hydrogen peroxide production under $1 \%(0.65 \%)$. 

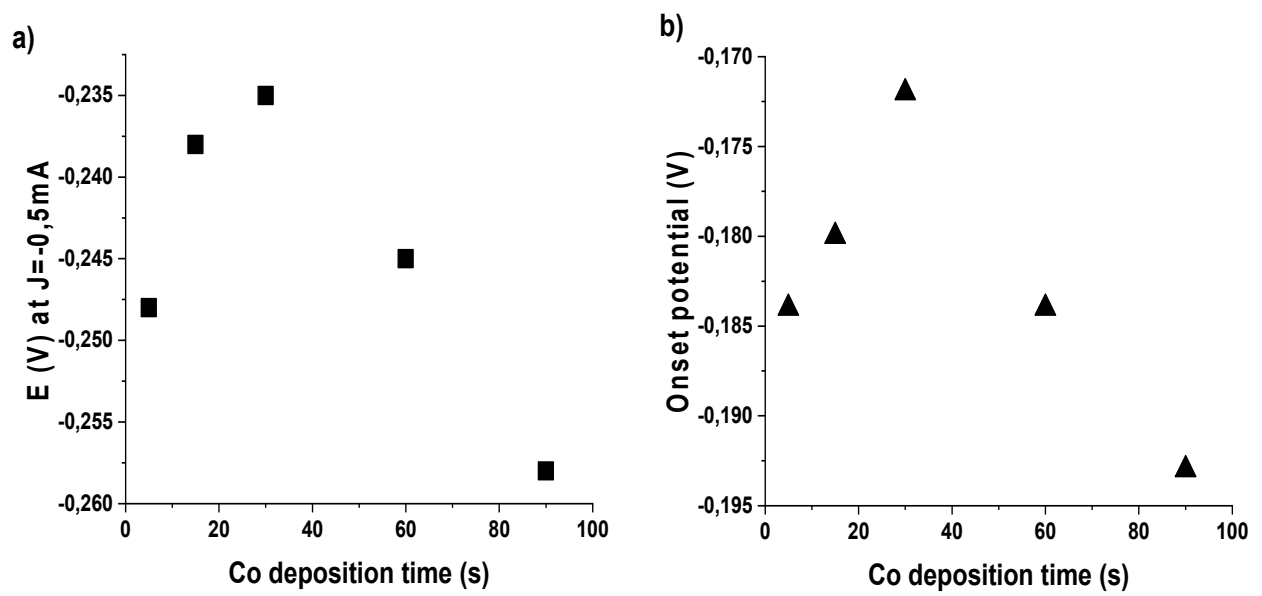

Figure 2. Volcano curves as obtained by plotting: (a) the potential values at $\mathrm{j}=-0.5 \mathrm{~mA} \cdot \mathrm{cm}^{-2}$; and (b) onset potential values versus time of Co electrochemical deposition.

To verify the stability of sample $\mathrm{CHecCo30s}$, it was tested for $10 \mathrm{~min}$ in an alkaline solution saturated with $\mathrm{O}_{2}$ at a potential of $-0.6 \mathrm{~V}$. In Figure 3, we can observe that under these conditions the number of exchanged electrons per oxygen molecule is maintained constant (near $4 \mathrm{e}^{-} / \mathrm{O}_{2}$ ) and thus their associated currents are without any loss of intensity, demonstrating a good stability. The ORR mechanism associated with our optimal sample implies the breakdown of the O-O bond without any intermediate steps by observing a $4 \mathrm{e}^{-}$exchange for $\mathrm{O}_{2}$ molecule, meaning a direct formation of water molecules.

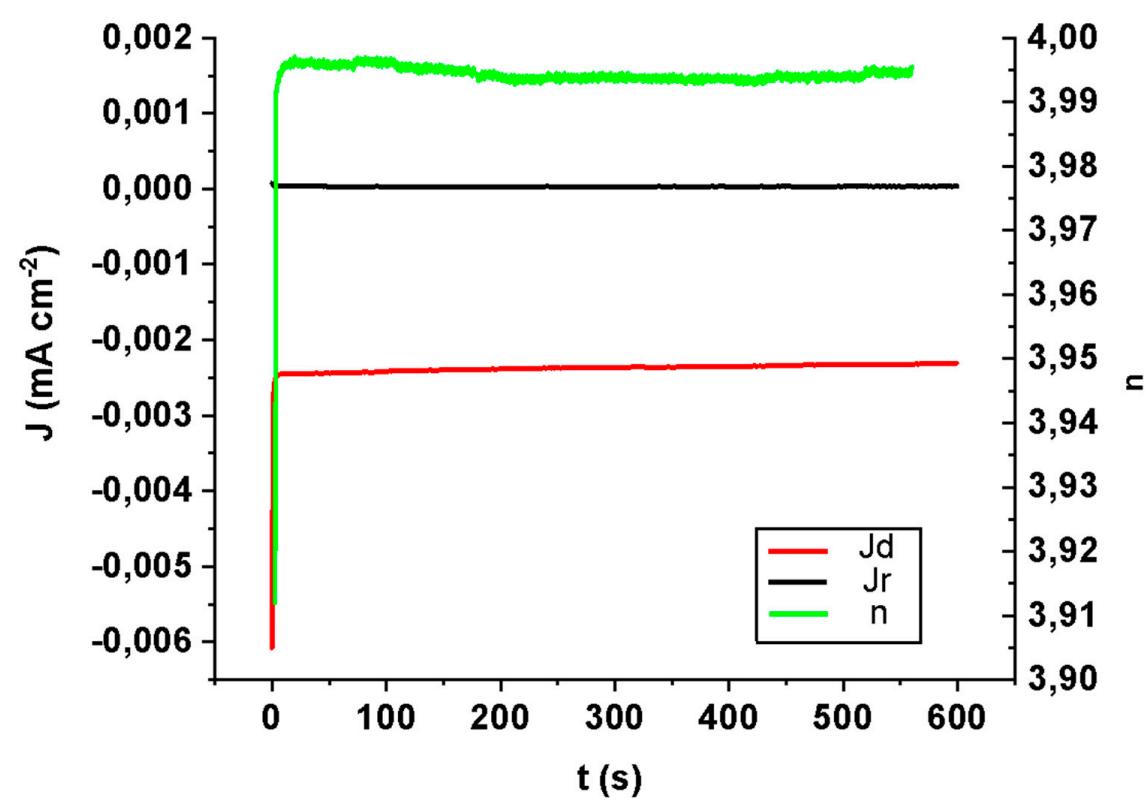

Figure 3. Time stability test (galvanostatic RRDE experiment) for a sample after electrochemical deposition of Co: ring and disk currents, together with $n$, the number of exchanged electrons per $\mathrm{O}_{2}$ molecule over time.

CHraw powder samples were investigated by STEM; overview HAADF images of typical char grains can be seen in Figure 4. Grains of submicron size show the presence of nanoparticles (indicated by the red arrows in Figure 4a). High-Resolution Bright Field (HR-BF) STEM images reveal the crystalline 
nature of the nanoparticles, as well as a mixed amorphous and graphitised char material (Figure 4c,d). EDX analysis on the nanoparticle shows they are made of Zn and S (Figure S8). Quantification of $\mathrm{Zn}$ and S signal using Cliff-Lorimer method in thin film approximation shows 1:1 ratio within the experimental error. These nanoparticles are the remnants of the vulcanisation process, as reported in [43]. The ORR mechanism is improved by the presence of the metal of these larger nanoparticles if compared to the simple carbon support. However, their effect is not at the same level as for the added Co material (see results for CHraw).
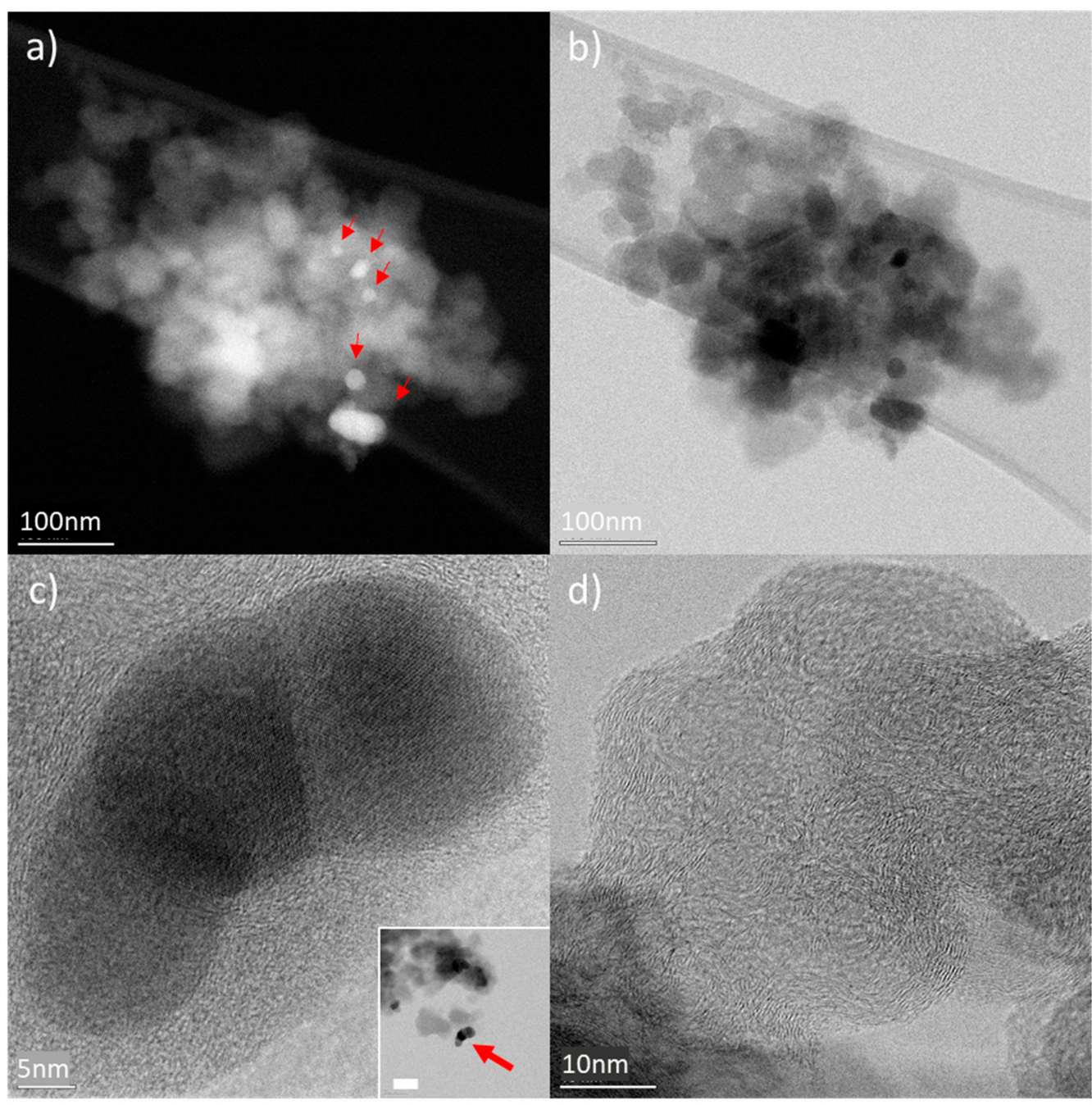

Figure 4. HAADF (a) and BF STEM (b) images of typical sub-micron clusters of raw char sample crashed powder supported by amorphous carbon film. Z contract in HAADF STEM images show the presence of inorganic nanocrystals (indicated by the red arrows). HR-BF STEM images of nanoparticles showing good crystallinity (a) as well as the degree of graphitisation of the char material (c). Inset in (c) shows an overview of the flake containing the nanoparticles (bar corresponds to $50 \mathrm{~nm}$ ).

The sample with optimal electrocatalytic performance corresponding to 30-s deposition (sample CHecCo30s) was investigated by STEM before and after electrocatalysis. The sample after electrodeposition shows a uniform coverage of Co in the form of a network-like structure, as shown in the HAADF images in Figure 5. Bigger Nanoparticles in Figure 5a are ZnS NPs, while whiter areas in Figure $5 b$ are associated to Nafion $\left(\mathrm{C}_{7} \mathrm{HF}_{13} \mathrm{O}_{5} \mathrm{~S} . \mathrm{C}_{2} \mathrm{~F}_{4}\right)$ residues. EDX analysis confirms their composition (see Figure S9). 


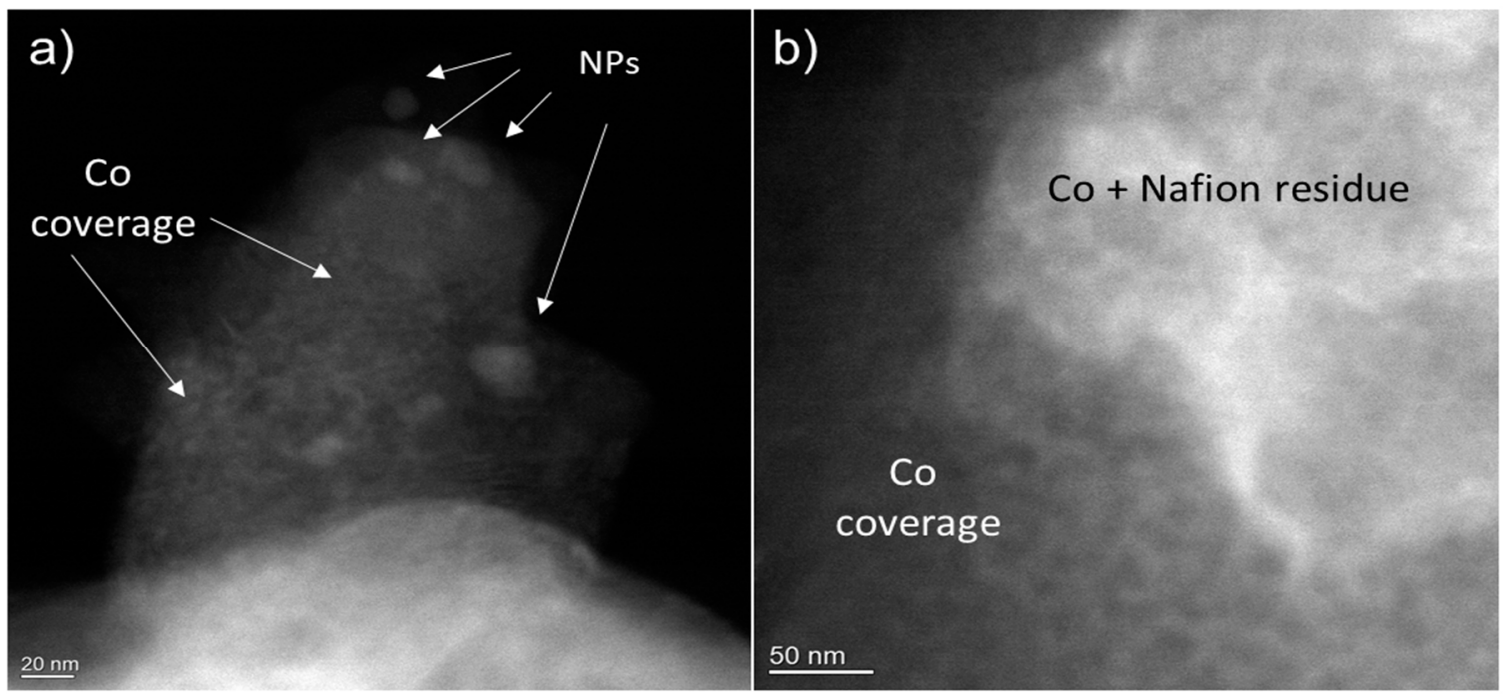

Figure 5. HAADF images of typical char grains after Co electrodeposition. Larger NPs in (a) are ZnS. Co is uniformly covering the grains surfaces with a network of islands. Whiter areas in (b) Contain fluorine due to the presence of residues of Nafion used to treat the sample. (see EDX analysis in Figure S9).

HAADF STEM images (Figure 6) show that after the stability measurements two types of materials with different textures can be observed on the chars: well defined nanoparticles and smaller accumulation of material at the edges of char grains. EDX analyses confirm that bigger nanoparticles are made of $\mathrm{Zn} \mathrm{S,} \mathrm{while} \mathrm{the} \mathrm{other} \mathrm{material} \mathrm{is} \mathrm{due} \mathrm{to} \mathrm{the} \mathrm{redistribution} \mathrm{of} \mathrm{Co} \mathrm{during} \mathrm{the} \mathrm{electrocatalysis}$ process where the Co network breaks up with migration of Co material towards the edges and grain boundaries of char (see elemental EDX analysis in Figure S10).
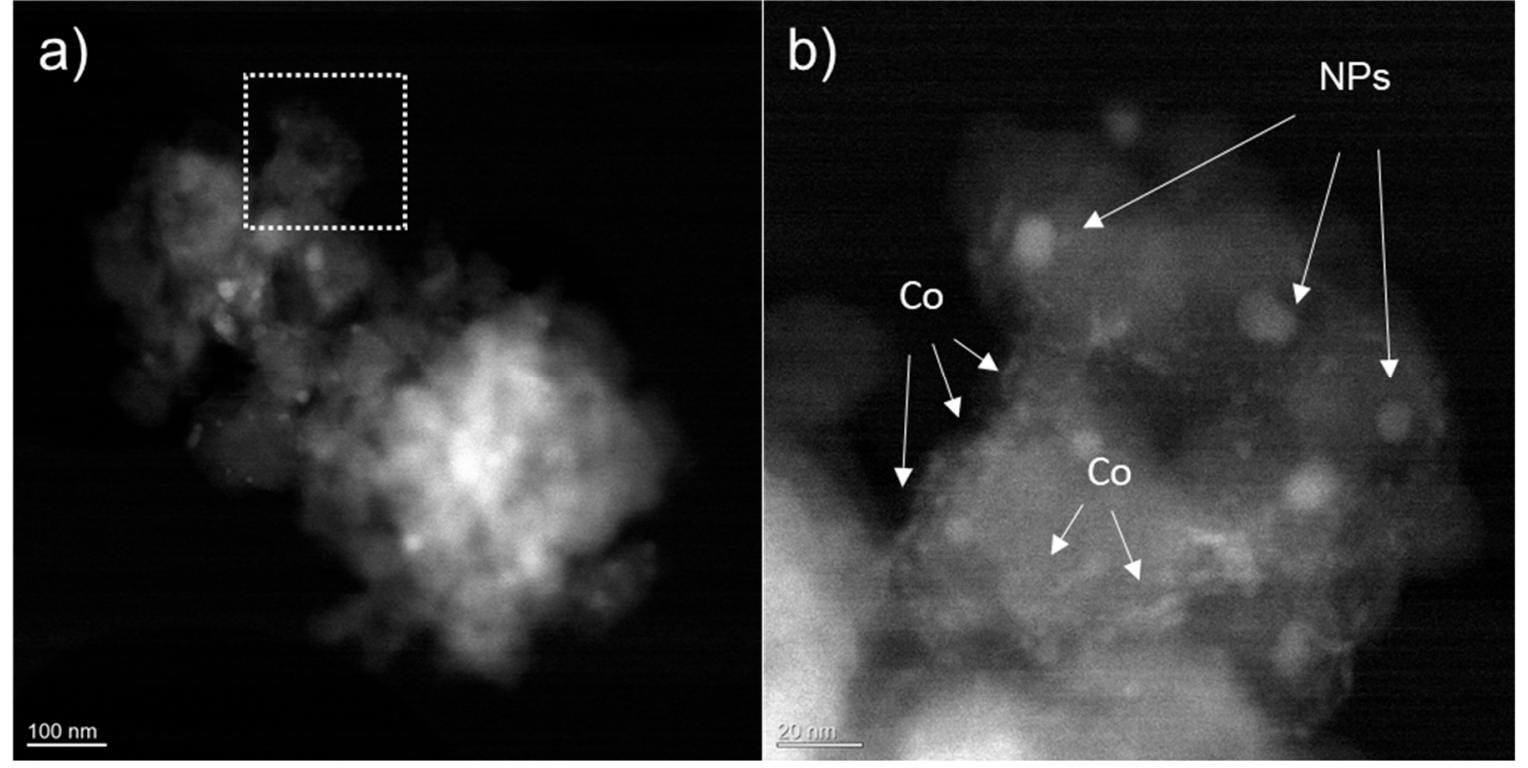

Figure 6. (a) HAADF STEM overview image showing a grain of material after stability measurements. (b) A higher magnification image corresponding to the dotted box areas in (a). Nanoparticles are visible as well as the remnant of the Co electrodeposited network.

High-resolution XPS spectra obtained in the ranges 815-765 and 1055-1015 eV around the Co $2 \mathrm{p}$ and $\mathrm{Zn} 2 \mathrm{p}$ transition, respectively, are reported in Figure 7. Spectra were acquired for samples 
before and after the stability measurements. The Zn $2 p$ profile remains the same with the addition of a shoulder towards high energy, indicating an increase in oxidation of the $\mathrm{ZnS}$ nanoparticles. A shift towards higher energies is visible in the Co peak, suggesting oxidation of the material. Such oxidation does not influence the catalytic efficiency of the cell, as shown in Figure 3.

(a)

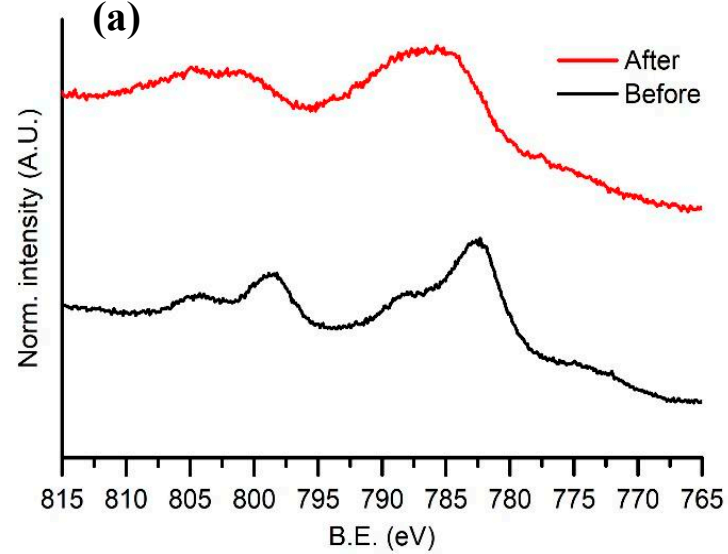

(b)

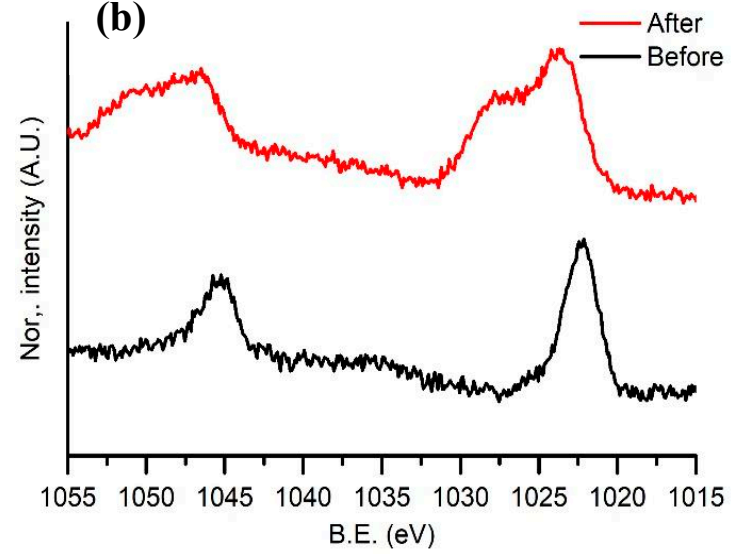

Figure 7. (a) High-resolution XPS for the Co 2p peaks in the range 815-765 eV. (b) High-resolution XPS for the $\mathrm{Zn} 2 \mathrm{p}$ peaks in the range $1055-1015 \mathrm{eV}$.

\section{Conclusions}

With the aim of finding an efficient substitute to noble metals in the catalysis of oxygen reduction reaction and at the same time to efficiently recycle waste automobile tyres, efforts have been made to strengthen the catalytic activity of chars obtained from MAP of waste tyres. Two metal enrichment methods, namely sonochemical and electrochemical deposition, were used to deposit $\mathrm{Co}$ and $\mathrm{Cu}$ on char. The catalytic efficiency of samples was evaluated by obtaining onset potential values and the number of exchanged electrons in oxygen reduction reaction in alkaline medium using hydrodynamic voltammetry RRDE technique. Samples enriched by electrochemical deposition were found to have better catalytic efficiency with respect to sonochemical deposited samples where excessive material was deposited on the char surfaces. Char electrodes enriched with Co show a maximum positive shift of $40 \mathrm{mV}$ with respect to raw char electrodes. This brings the number of exchanged electrons per $\mathrm{O}_{2}$ molecule during ORR close to 4 (Pt value) corresponding to a reduction in the production of unwanted oxygen peroxide from $23 \%$ for raw chars to $1 \%$ for the optimal deposition conditions of $\mathrm{CHecCo30s}$ sample. In addition, chars deposited with sonochemical $\mathrm{Cu}$, although showing a similar onset potential as for the optimal Co samples, resulted in a production of $40 \% \mathrm{H}_{2} \mathrm{O}_{2}$ corresponding to a reduced catalytic efficiency.

Galvanostatic measurements of the optimal sample show good catalytic efficiency stability over time. STEM analyses show a uniform network-like Co coverage of the char surface before the stability test, whereas material rearrangement is observed after it. XPS analysis shows Co slightly oxidised after the treatment. Both changes did not seem to interfere with the efficiency of the semi-cell.

This study proved that it is possible to increase the catalytic activity of chars after deposition of an inexpensive metals such as $\mathrm{Co}$ : waste char derived from end of life tyres can be easily transformed without expensive treatments in both economic and energetic terms to produce green energy.

Supplementary Materials: The following are available online at http://www.mdpi.com/1996-1073/13/21/5646/s1.

Author Contributions: Investigation, M.P., L.L., G.S. and L.R.; writing—original draft preparation, M.P., M.B., F.B., L.L. and W.G.; writing-review and editing, M.P., L.L., M.B., F.B., W.G., L.F. and M.V.; supervision, L.R., C.F., V.K.L. and M.I.; project administration, M.I.; and funding acquisition, M.I., L.L. and V.K.L. All authors have read and agreed to the published version of the manuscript. 
Funding: L.L. and M.P. acknowledge L. Giotti for fruitful discussions. L.L. acknowledges financial support from the University of York Research Theme Champions' Travel and Networking Fund for the project "From Landfill to Green Energy". The authors also acknowledge PRIN ("Progetti di Ricerca di Rilevante Interesse Nazionale"), which made possible the project "Novel Multilayered and Micro-Machined Electrode Nano-Architectures for Electrocatalytic Applications (Fuel Cells and Electrolyzers)", grant number 2017YH9MRK.

Conflicts of Interest: The authors declare no conflict of interest.

\section{References}

1. Pantea, D.; Darmstadt, H.; Kaliaguine, S.; Roy, C. Heat-treatment of carbon blacks obtained by pyrolysis of used tires. Effect on the surface chemistry, porosity and electrical conductivity. J. Anal. Appl. Pyrolysis 2003, 67, 55-76. [CrossRef]

2. Basu, P. Pyrolysis. In Biomass Gasification, Pyrolysis and Torrefaction; Elsevier: Amsterdam, The Netherlands, 2013; pp. 147-176.

3. Gasparatos, A.; von Maltitz, G.P.; Johnson, F.X.; Lee, L.; Mathai, M.; Puppim de Oliveira, J.A.; Willis, K.J. Biofuels in sub-Sahara Africa: Drivers, impacts and priority policy areas. Renew. Sustain. Energy Rev. 2015, 45, 879-901. [CrossRef]

4. Chen, K.-S.; Lin, Y.-C.; Hsu, K.-H.; Wang, H.-K. Improving biodiesel yields from waste cooking oil by using sodium methoxide and a microwave heating system. Energy 2012, 38, 151-156. [CrossRef]

5. Wang, Y.; Balbuena, P.B. Design of Oxygen Reduction Bimetallic Catalysts: Ab-Initio-Derived Thermodynamic Guidelines. J. Phys. Chem. B 2005, 109, 18902-18906. [CrossRef]

6. Yang, D.-S.; Chaudhari, S.; Rajesh, K.P.; Yu, J.-S. Preparation of Nitrogen-Doped Porous Carbon Nanofibers and the Effect of Porosity, Electrical Conductivity, and Nitrogen Content on Their Oxygen Reduction Performance. Chem CatChem 2014, 6, 1236-1244. [CrossRef]

7. Eisenberg, D.; Stroek, W.; Geels, N.J.; Sandu, C.S.; Heller, A.; Yan, N.; Rothenberg, G. A Simple Synthesis of an N-Doped Carbon ORR Catalyst: Hierarchical Micro/Meso/Macro Porosity and Graphitic Shells. Chem.- $A$ Eur. J. 2016, 22, 501-505. [CrossRef]

8. Khan, I.A.; Qian, Y.; Badshah, A.; Nadeem, M.A.; Zhao, D. Highly Porous Carbon Derived from MOF-5 as a Support of ORR Electrocatalysts for Fuel Cells. ACS Appl. Mater. Interfaces 2016, 8, 17268-17275. [CrossRef]

9. Ansari, M.S.; Jebakumar Immanuel Edison, T.N.; Lee, Y.R. Enhanced electrocatalytic and supercapacitive performance using the synergistic effect of defect-rich N/S co-doped hierarchical porous carbon. Sustain. Energy Fuels 2020. [CrossRef]

10. Khan, Z.; Park, S.O.; Yang, J.; Park, S.; Shanker, R.; Song, H.-K.; Kim, Y.; Kwak, S.K.; Ko, H. Binary N,S-doped carbon nanospheres from bio-inspired artificial melanosomes: A route to efficient air electrodes for seawater batteries. J. Mater. Chem. A 2018, 6, 24459-24467. [CrossRef]

11. Kim, S.; Park, H.; Li, O.L. Cobalt Nanoparticles on Plasma-Controlled Nitrogen-Doped Carbon as High-Performance ORR Electrocatalyst for Primary Zn-Air Battery. Nanomaterials 2020, 10, 223. [CrossRef]

12. Passaponti, M.; Rosi, L.; Frediani, M.; Salvietti, E.; De Luca, A.; Giaccherini, A.; Innocenti, M. Microwave Assisted Pyrolysis of Waste Tires: Study and Design of Half-Cells SOFCs with Low Environmental Impact. ECS Trans. 2017, 78, 1933-1940. [CrossRef]

13. Grdeń, M.; Jagiełło, J. Oxidation of electrodeposited cobalt electrodes in an alkaline electrolyte. J. Solid State Electrochem. 2013, 17, 145-156. [CrossRef]

14. Erts, D.; Ahlberg, E.; Asbjörnsson, J.; Olin, H.; Prikulis, J. Studies of the initial oxidation of cobalt in alkaline solutions using scanning electrochemical microscope. Appl. Phys. A Mater. Sci. Process. 1998, 66, S477-S480. [CrossRef]

15. Wang, Y.; Zhang, D.; Liu, H. A study of the catalysis of cobalt hydroxide towards the oxygen reduction in alkaline media. J. Power Sources 2010, 195, 3135-3139. [CrossRef]

16. Ohsaka, T.; Mao, L.; Arihara, K.; Sotomura, T. Bifunctional catalytic activity of manganese oxide toward O2 reduction: Novel insight into the mechanism of alkaline air electrode. Electrochem. Commun. 2004, 6, $273-277$. [CrossRef]

17. Wu, J.; Zhang, D.; Wang, Y.; Wan, Y.; Hou, B. Catalytic activity of graphene-cobalt hydroxide composite for oxygen reduction reaction in alkaline media. J. Power Sources 2012, 198, 122-126. [CrossRef]

18. Dai, X.; Nekrassova, O.; Hyde, M.E.; Compton, R.G. Anodic Stripping Voltammetry of Arsenic(III) Using Gold Nanoparticle-Modified Electrodes. Anal. Chem. 2004, 76, 5924-5929. [CrossRef] 
19. Banks, C.E.; Davies, T.J.; Wildgoose, G.G.; Compton, R.G. Electrocatalysis at graphite and carbon nanotube modified electrodes: Edge-plane sites and tube ends are the reactive sites. Chem. Commun. $2005,829$. [CrossRef]

20. Zhong, Z.; Chen, H.; Tang, S.; Ding, J.; Lin, J.; Lee Tan, K. Catalytic growth of carbon nanoballs with and without cobalt encapsulation. Chem. Phys. Lett. 2000, 330, 41-47. [CrossRef]

21. Katz, E.; Willner, I.; Wang, J. Electroanalytical and Bioelectroanalytical Systems Based on Metal and Semiconductor Nanoparticles. Electroanalysis 2004, 16, 19-44. [CrossRef]

22. Welch, C.M.; Compton, R.G. The use of nanoparticles in electroanalysis: A review. Anal. Bioanal. Chem. 2006, 384, 601-619. [CrossRef] [PubMed]

23. Kaluža, L.; Larsen, M.J.; Zdražil, M.; Gulková, D.; Vít, Z.; Šolcová, O.; Soukup, K.; Koštejn, M.; Bonde, J.L.; Maixnerová, L.; et al. Highly loaded carbon black supported Pt catalysts for fuel cells. Catal. Today 2015, 256, 375-383. [CrossRef]

24. Kaluža, L.; Larsen, M.J.; Morales, I.J.; Cavaliere, S.; Jones, D.J.; Rozière, J.; Kallistová, A.; Dytrych, P.; Gulková, D.; Odgaard, M. Synthesis of Pt/C Fuel Cell Electrocatalysts: Residual Content of Chloride and Activity in Oxygen Reduction. Electrocatalysis 2016, 7, 269-275. [CrossRef]

25. Liu, S.; Yu, J.; Ju, H. Renewable phenol biosensor based on a tyrosinase-colloidal gold modified carbon paste electrode. J. Electroanal. Chem. 2003, 540, 61-67. [CrossRef]

26. Meille, V. Review on methods to deposit catalysts on structured surfaces. Appl. Catal. A Gen. 2006, 315, 1-17. [CrossRef]

27. Strong, F.C. Faraday's laws in one equation. J. Chem. Educ. 1961, 38, 98. [CrossRef]

28. Zafferoni, C.; Cioncoloni, G.; Foresti, M.; Dei, L.; Carretti, E.; Vizza, F.; Lavacchi, A.; Innocenti, M. Synergy of Cobalt and Silver Microparticles Electrodeposited on Glassy Carbon for the Electrocatalysis of the Oxygen Reduction Reaction: An Electrochemical Investigation. Molecules 2015, 20, 14386-14401. [CrossRef]

29. Okitsu, K.; Bandow, H.; Maeda, Y.; Nagata, Y. Sonochemical Preparation of Ultrafine Palladium Particles. Chem. Mater. 1996, 8, 315-317. [CrossRef]

30. Mizukoshi, Y.; Okitsu, K.; Maeda, Y.; Yamamoto, T.A.; Oshima, R.; Nagata, Y. Sonochemical Preparation of Bimetallic Nanoparticles of Gold/Palladium in Aqueous Solution. J. Phys. Chem. B 1997, 101, 7033-7037. [CrossRef]

31. Gedanken, A. Using sonochemistry for the fabrication of nanomaterials. Ultrason. Sonochem. 2004, 11, 47-55. [CrossRef]

32. Riesz, P.; Berdahl, D.; Christman, C.L. Free radical generation by ultrasound in aqueous and nonaqueous solutions. Environ. Health Perspect. 1985, 64, 233-252. [CrossRef] [PubMed]

33. Undri, A.; Sacchi, B.; Cantisani, E.; Toccafondi, N.; Rosi, L.; Frediani, M.; Frediani, P. Carbon from microwave assisted pyrolysis of waste tires. J. Anal. Appl. Pyrolysis 2013, 104, 396-404. [CrossRef]

34. Wang, C.; Qu, T.; Wang, D.; Kang, Z. Synthesis of Co-Fe-Pd nanoparticles via ultrasonic irradiation and their electro-catalytic activity for oxygen reduction reaction. Appl. Catal. A Gen. 2018, 560, 103-110. [CrossRef]

35. Ruiz-Camacho, B.; Martínez Álvarez, O.; Rodríguez-Santoyo, H.H.; López-Peréz, P.A.; Fuentes-Ramírez, R. Mono and bi-metallic electrocatalysts of $\mathrm{Pt}$ and $\mathrm{Ag}$ for oxygen reduction reaction synthesized by sonication. Electrochem. Commun. 2015, 61, 5-9. [CrossRef]

36. Lari, L.; Nuttall, C.J.; Copley, M.P.; Potter, R.J.; Simon, J.; Mingo, N.; Ozkaya, D. Characterization of nanoembedded alloyed thermoelectrics. J. Phys. Conf. Ser. 2014, 522, 012040. [CrossRef]

37. Muniz-Miranda, M.; Muniz-Miranda, F.; Caporali, S.; Calisi, N.; Pedone, A. SERS, XPS and DFT investigation on palladium surfaces coated with 2,2'-bipyridine monolayers. Appl. Surf. Sci. 2018, 457, 98-103. [CrossRef]

38. Calisi, N.; Caporali, S.; Milanesi, A.; Innocenti, M.; Salvietti, E.; Bardi, U. Composition-Dependent Degradation of Hybrid and Inorganic Lead Perovskites in Ambient Conditions. Top. Catal. 2018, 61, 1201-1208. [CrossRef]

39. Borri, C.; Calisi, N.; Galvanetto, E.; Falsini, N.; Biccari, F.; Vinattieri, A.; Cucinotta, G.; Caporali, S. First Proof-of-Principle of Inorganic Lead Halide Perovskites Deposition by Magnetron-Sputtering. Nanomaterials 2019, 10, 60. [CrossRef]

40. Bagotzky, V.S.; Tarasevich, M.R.; Radyushkina, K.A.; Levina, O.A.; Andrusyova, S.I. Electrocatalysis of the oxygen reduction process on metal chelates in acid electrolyte. J. Power Sources 1978, 2, 233-240. [CrossRef]

41. Passaponti, M.; Savastano, M.; Clares, M.P.; Inclán, M.; Lavacchi, A.; Bianchi, A.; García-España, E.; Innocenti, M. MWCNTs-Supported Pd(II) Complexes with High Catalytic Efficiency in Oxygen Reduction Reaction in Alkaline Media. Inorg. Chem. 2018, 57, 14484-14488. [CrossRef] 
42. Medford, A.J.; Vojvodic, A.; Hummelshøj, J.S.; Voss, J.; Abild-Pedersen, F.; Studt, F.; Bligaard, T.; Nilsson, A.; Nørskov, J.K. From the Sabatier principle to a predictive theory of transition-metal heterogeneous catalysis. J. Catal. 2015, 328, 36-42. [CrossRef]

43. Passaponti, M.; Rosi, L.; Savastano, M.; Giurlani, W.; Miller, H.A.; Lavacchi, A.; Filippi, J.; Zangari, G.; Vizza, F.; Innocenti, M. Recycling of waste automobile tires: Transforming char in oxygen reduction reaction catalysts for alkaline fuel cells. J. Power Sources 2019, 427, 85-90. [CrossRef]

Publisher's Note: MDPI stays neutral with regard to jurisdictional claims in published maps and institutional affiliations.

(C) 2020 by the authors. Licensee MDPI, Basel, Switzerland. This article is an open access article distributed under the terms and conditions of the Creative Commons Attribution (CC BY) license (http://creativecommons.org/licenses/by/4.0/). 